\title{
Xing Zhou* \\ The Current Problems of Aesthetic Creation in Chinese Film Art
}

https://doi.org/10.1515/jcfs-2021-0031

Published online November 24, 2021

\begin{abstract}
Current market-led Chinese film production has made huge achievements. Market indicators certainly have their validity. However, the power of the market has been exaggerated so that it controls everything. Because of the disregard of film as an aesthetic object, the content, form and aesthetic sensibility of films have been neglected, preventing creation at a higher level. The loss of multiple cultural identities due to market factors and artistic indifference is hardly sustainable in the long run. In recent years, Chinese films have gradually improved their artistic aesthetics. How to reasonably coordinate the market and the realization of the value of art and culture itself is an urgent problem to be solved. Firstly, Chinese films should have creative imagination; secondly, Chinese films should have the artistic expression of the national core value of heroism; thirdly, Chinese films should have meticulous depictions of people. Under the perspective of aesthetic appreciation, it is a top priority for Chinese films to be more in line with reality and traditional aesthetic culture, and be more characterized in their creation.
\end{abstract}

Keywords: Chinese cinema, aesthetic spirit, characterized creation

Translated by: Zixuan Gu, Communication University of China, Beijing, China.

\section{The Problem Raised in the Current Chinese Cinema}

Nominated for the Academy Award for Best International Feature Film in 2021, Better Days (Shaonian de ni, 2019) has become an excellent example of Chinese cinema that balances artistic expression and market demand, although it did not win the award in the end. Thus, taking the ups and downs of Chinese cinema in the

*Corresponding author: Xing Zhou, Beijing Normal University, Beijing, China, E-mail: xcnz001@163.com 
past five years as an object of observation, its reflection of the current state of the film industry is quite in line with Chinese characteristics. For example, after experiencing a worrying market decline in 2017, Chinese cinema climbed up again at the end of July and resumed a sound market situation. In September 2017, award-winning films of the 74th Venice Film Festival were released, with all Chinese nominated films out of the game. One of the award-winning films, eyecatching Israeli film Foxtrot (פוֹקִסטרוֹ, 2017), won the Grand Jury Prize, was considered a philosophical film not aiming to please the market. It is reported that "After eight years, Samuel Maoz, the Israeli director who won the Golden Lion at the 66th Venice Film Festival for Lebanon (לבנון, 2009), is nominated again in the main competition of the Venice Film Festival with his new film Foxtrot. The foxtrot is a four-step dance that originated from black Americans and also hints at the fate of the characters in the story: no matter how much they dance, they end up back where they started. The foxtrot is also an army code word. The film is a strong critique of the Israeli authorities' reckless recruitment of young soldiers. Foreign media were skeptical that audiences would be able to decipher the political metaphors in the film, which The Hollywood Reporter called a "surreal dance of destiny with nowhere to hide" (Xiao 2017). The reason for citing art-philosophical film reviews is that it is customary to judge a film by its entertainment value, and films with deep thoughts are usually denigrated by both the market and reviews. We have heard and seen a number of creations that have been favored by film festivals for their representation and reflection on reality, because while entertainment is often fleeting, thoughts live forever. In this way, it is not difficult to discover that in the process of Chinese cinema, the light of thoughts is relatively dim in the development process in which entertainment prevails. Whether it is Back to 1942 (Yi jiu si er, 2012) and I Am Not Madame Bovary (Wobushi Pan jinlian, 2016) directed by Feng Xiaogang, taking an unusual path to compete with ordinary Chinese New Year's films, or Coming Home (Guilai, 2014) directed by Zhang Yimou, etc., they all encounter unsatisfactory market responses and divergent critiques. However, with films such as Operation Mekong (Meigonghe xingdong, 2016), Wolf Warriors 2 (Zhanlang, 2017), Dying to Survive (Wo bushi yaoshen, 2018), My People, My Country (Wo he wode zuguo, 2019), So Long, My Son (Dijiu tianchang, 2019), Better Days, A Little Red Flower (Songni yiduo xiaohonghua, 2020), and Cliff Walkers (Xuanya zhishang, 2021) as the core, Chinese cinema has reached a balance between aesthetic appreciation and market demand. We need to further explore the gains and losses in development, and the reasons for the transformation of aesthetic expression in Chinese cinema.

The tremendous achievements of Chinese cinema in recent years cannot be ignored, with the scale of the domestic market approaching the scale of the number one market, North America. Despite slow growth in 2016 and 2017, the market was 
on the rise at the end of July 2017 because of the popularity of Wolf Warriors 2 and others, and "On September 4th, the total box office of the Chinese mainland movie market reached 40 billion this year, 74 days faster than last year's breakthrough of this figure" (Dong 2017). People were speculating when will be the soonest point that the box office of 2017 exceeds 50 billion, as 2017 "Saw a total of 347 movies released in the first eight months. Among them, 290 domestic films reached a box office of 21 billion. Overseas imported films only 57, but reached a box office of 19 billion. From this set of figures, it is obvious that the overall strength of domestic films is still weak, and the average box office is far less than that of overseas films" (Dong 2017). But this year, the total box office of Chinese films and domestic films unexpectedly relied on the one film Wolf Warriors 2, which reached a superb box office of 5.5 billion yuan; otherwise the situation would be very different. Obviously, Wolf Warriors 2 has a unique pursuit different from that of yielding to the market, proving that simply taking the market as the only metric is not necessarily a good recipe for achieving good results. From another perspective, we are also worried that apart from Wolf Warriors 2, can there be other creative works to support Chinese cinema continuously?

In 2018 and 2019, the Chinese film market overcame various setbacks and progressed, after the so-called "black swan" incidents, capital power became skeptical of market investments and people saw the "cold winter" of Chinese cinema coming. However, unexpectedly, the resilient Chinese cinema market overcame the difficulties, with the total box office of national films in 2018 slightly exceeding the 60 billion yuan, reaching 60.976 billion yuan, which achieved a rise of $9.06 \%$ from 55.911 billion yuan in 2017. In 2019, the "warm spring”, instead of the "cold winter" that people had kept worrying about, appeared in the industry, with a market revenue of 64.266 billion yuan, ranking the second in the global box office. The reason for this turnaround is the emergence of increasingly excellent works that are popular with audiences and excel in aesthetic expression. Obviously, however, the power of the market has been exaggerated so that it controls everything. Market indicators are certainly justified and indispensable for the achievement of national strategic goals of film development. Because of the disregard of film as an aesthetic object, the content, form and the aesthetic sensibility of films are lost, which prevents creation at a higher level. We have already found that in the case of succumbing to market factors, there is a certain loss of plural cultural identities, and films that used to be able to gain recognition from the world are unable to get enough support because of the indifference to art and culture, while market films lack longevity due to their utilitarian nature. It is the norm, but certainly not a healthy condition, for artistic films to be less likely to gain favor in the market. However, in recent years, strong demand for content products from audiences, as well as the demand for aesthetic heroism, can be seen in films 
like Operation Mekong and Wolf Warriors 2, driving the progress of Chinese cinema. How to dialectically examine the aesthetic value of film, and how to reasonably balance market pressures with the realization of artistic value have become urgent problems to be solved in development.

Of course, it is impossible to avoid the conflict between art and the market. Observing the current Chinese cinema from the perspective of aesthetic expression, one must admit that current Chinese cinema is already quite rich in terms of genres. It is true that Chinese cinema, which takes the market as its guideline, competes with other countries for a larger market share, with industrialization as its metric. There's nothing wrong with that. We are slowly adopting the market success of Chinese cinema and the popularity of audiences as the only criteria. In the past decade, the Chinese film market is becoming more and more focused on market demand and increasingly neglecting the aesthetic value of film, thereby reducing the vibrance of Chinese aesthetics and narrowing the cultural pluralism of cinema. The existence of the market, which is supposed to enable the existence of diverse aesthetic cultures, has actually caused aesthetic culture to give way to the utility and entertainment demands of the market. The aesthetic culture of film is certainly inclusive, but it is gradually disappearing. Why is it increasingly obvious that movies that are well received by audiences do not sell well at the box office, while movies that sell well at the box office are often criticized by audiences? Why is it that, the higher the box office, the harder it is to get critical acclaim for a film? And what they consider to be good films are not valued by the general public. The crux of the problem is that aesthetic standards are increasingly being neglected. In the era when the administrative system managed film production, films were originally regarded as cultural objects, and film content was given more importance. This is why, in the absence of a mature market environment and under the guidance of a planned economy, a seemingly irrational system has given birth to many outstanding works in Chinese cinema, recognized by the world. Culture measures out the content, fixed aesthetics take the main position. From the view of producers, the audience and relevant institutions, they are still standard bearers, achieving the balance between art and market. We have no intention to get rid of the preeminence of the market and to regress to the administrative film system. It is impossible to turn back the clock. But we have to see that when the market dominates to a certain extent, aesthetic culture must be strongly stimulated so that art and the market can reach a balance to avoid a situation where the market is the only priority. There are various kinds of good films gaining positive reviews in the market, but films with artistic merit should never be absent in the market. The value of aesthetic creation in history includes films produced by directors of the fourth and fifth generations as well as those of the third generation, since works that have passed the test of time naturally endure throughout history. This also 
includes the films that have won awards at world film festivals and are still recognized under various political or cultural views. Individual expression and aesthetic experimentation are sure to produce outstanding works with lasting historical value. There is no reason to devalue or suppress aesthetic culture for the sake of market development, as it is the essential element of film. It is time to seriously consider why the market has been booming in the past decade or so, while aesthetic culture lags behind, and how film art can be developed in a more harmonious way. As a result, it has become common practice for Chinese films nominated for the Academy Awards not to be selected, even less so than in the golden age of the fifth generation. At that time, almost all the world film festivals regretted that there were no Chinese films in competition. The reason seems to be that neither the producers, nor the audience, or the commentators can discard the market as an important metric, and thus neglects art and culture. While commercial entertainment films such as Tiny Times (Xiao shidai, 2013) achieved market success, such films were criticized by the audiences, while leading to the emergence of a large number of films that disregard art and culture, human thinking and real-life considerations, and a tendency for the creators' conceptual orientation and the public's aesthetics to become increasingly indifferent. The danger is that we are slowly acquiescing to the fact that films created by art and culture cannot gain recognition in the market. If not for some good films in recent years, such as Operation Mekong and Wolf Warriors 2, which have provoked positive responses, we would even wonder if this unreasonable backlash has really become a reasonable existence for Chinese cinema. The good thing is that with the development of the times and the emphasis on artistic and cultural performance, the state of art has undergone many changes. In 2018, director Wen Muye's Dying to Survive has brought an outstanding presentation of realism; in 2019, director Frant Gwo's The Wandering Earth (Liulang diqiu, 2019) has embarked on a new journey for Chinese science fiction films, director Yang Yu's Nezha: Birth of the Demon Child (Nezha zhi motong jiangshi, 2019) has broken through the old customs of artistic performance in animation; at the beginning of the same year, Wang Xiaoshuai's So Long, My Son has been especially impressive for its artistic charm of moral tradition restoration; and at the end of the year, director Derek Tsang's Better Days has exposed school bullying and shown the human struggle for good. This reveals to us that art and culture from a cultural point of view is an essential factor in the value of cinema. It is absolutely indispensable for the grasp of human emotions. 


\section{The Importance of the Aesthetic Spirit}

There is no doubt that Chinese cinema needs to pay attention to the market. Chinese cinema has just embarked on the road of market transformation, and the navigation of the market may not be perfect, even though the market is closely related to the development of Chinese cinema. Therefore, it is reasonable to make market construction, especially the resistance to Hollywood and the maintenance of our own market share in the long run, into necessary initiatives. But it seems that we have reached a new stage. It is the time to produce films with excellent artistic content on the basis of a certain market development, especially when the market suffered a declining development from 1976 to the first half of 2017. It is time to shift from the market-dominated mindset to a two-pronged approach to developing Chinese films. On the one hand, we should continue to build the market by producing high-quality films with large investments and high-end technology, in order to secure our major market share and provide a good environment for artistic production. On the other hand, we need to support diverse works of high artistic quality that are not supported by the market, or that need market support to reach more people, in order to foster a healthy market atmosphere in the long run. A balance needs to be struck between the two concerns.

Most importantly, our indifference to artistic aesthetics is obviously detrimental to the development of cinema, because after all, cinema is first and foremost an artistic product, which needs to guide people's spirituality and artistic aesthetics. Without support for art in the market, films would become pure entertainment, and it would be impossible for them to develop in the long run because of their homogeneity and weakness. Many examples prove that neither the complete neglect of the market nor the total worship of it can establish a wellrounded film production system. Focusing on artistic and aesthetic production of film meets the demand of the people and the art market, which can be the breakthrough point for the bottleneck encountered in the further development of Chinese cinema. The situation in recent years has been a wake-up call for us. Apart from the lack of awards won by Chinese films in world film festivals, artistic films are gradually gaining popularity among people who are tired of entertainment parodies, revealing the creative value of artistic production for satisfying people's emotional needs. For example, Documentary Twenty Two (Ershier, 2017), reached 170 million yuan at the box office, exceeding everyone's expectations. The director originally expected 10 million but got more than 10 times in the end. The media said, “This is a documentary featuring 'comfort women' survivors, with a serious theme and an introverted mood; and the figure of 170 million yuan is twice the total box office of Chinese documentary films last year (82.92 million yuan). Thus, it has 
become another phenomenal film worth discussing in this summer season, in addition to Wolf Warriors 2" (Liu 2017). Previously the documentary Paths of the Soul (Kang rinpoche, 2015) was also praised for surpassing the 100 million box office. In a certain sense, Wu Jing's film Wolf Warriors 2 has created a box office miracle and surpassed people's expectations. It is not just an action film or a gunfight movie, but a film reflecting the reality, echoing people's expectation that Chinese people should establish their own position in the world, and that Chinese people expect heroism in visual culture. All of the above-mentioned films of different types have succeeded because of their distinctive artistic expression. Twenty Two or Paths of the Soul focus on the drama of the human heart from a documentary perspective. They are not the favorites of the market, yet they have received extremely high market returns. This means that more works with artistic ambitions should provide a good basis for a new leap forward in Chinese cinema. On the other hand, art films perhaps reflect reality and people's hearts, combining commercial elements with artistic elements to produce greater cultural elements. Our emphasis on the success of the combination of art and market tells us that art film is the comfort of the heart and needs the echoes of the market.

The reconciliation of art to the market is surprisingly successful in Wolf Warriors 2, which proves that a good market lacking artistic emotion will not be able to reach this high box office of more than 5.6 billion yuan. On the contrary, a serious problem lies in the artistic expression, or the transmutation of aesthetics. Chinese cinema needs to recreate art films with Chinese characteristics. Films that merely gain the esteem of Hollywood may not resonate with audiences. At the same time, even if Wolf Warriors 2 has gone from lukewarm to hot at the box office in the Hong Kong market, it is not revered in the Western market and is considered to propagate a long-outdated heroism. "Some netizens have posted the release of Wolf Warriors 2 in some overseas cinemas. It is reported that the film will land in the cinemas of major cities in the UK, and is currently being screened in three cities, Manchester, Sheffield and Philips first. And there are some theaters that have sold out of tickets, which shows the popularity of the film" (Fu 2017). One month later, it was reported that "Wolf Warriors 2 has been a constant topic of conversation since its release on July 27, with a box office of over 5.65 billion. Not only that, it was also released in Germany with an $80 \%$ attendance rate and was widely acclaimed by the audience. Frank Grillo, who plays the villain in Wolf Warriors 2, told Chinese media that several Hollywood studios had sent offers to director Wu Jing, with more than a dozen phone calls a day asking if Wu Jing could speak English" (Btime 2017). Of course, we must first take the preferences of the Chinese audience as the priority, so it is necessary to promote heroism and patriotism as the basic aesthetics. This will at least meet the needs of the current market, and be in line with the direction pursued by Chinese people today, and then furthermore have a 
more ambitious pursuit. To achieve this more ambitious pursuit, we need to promote, foster and cultivate more artistic films, including documentary films, films that deeply express people's emotions, films that reflect reality and have profound meanings, and of course films that express the daily life of ordinary people. Chinese cinema needs good films with such cultural and artistic traits, and the Chinese film market needs to rely on good films with such aesthetic ambitions to improve its overall quality. What's more, people need to perceive the beautiful spirit in an aesthetic atmosphere and improve their aesthetic capacities.

With the emphasis on artistic expression, some films with excellent artistic expression in recent years have made up for the shortcomings of the past films. For example, Tibetan director Pema Tseden's 2020 film Balloon (Qiqiu, 2020) represents people's daily lives in an original way, but reveals the profound emotional entanglement of human nature. The artistic expression of his previous work Jinpa (Zhuangsi yizhi yang, 2018) is also memorable. Particular mention should be made of the outstanding film of the new mainstream creation My People, My Country in 2019, which combines the daily lives of ordinary people with the major event of the 70th anniversary of the founding of New China, and the sensitivity of its artistic expression has won universal acclaim from the public.

\section{Gains and Losses During the Aesthetic Transformation}

When analyzing artistic expression in the current Chinese film market boom, it is time to take a serious look at the process of strengthening the aesthetics of film art and remedying its defects. It is good to expect a healthy interaction between art and the market, but most of the time, we cannot ignore the utilitarian hazards caused by the loss of artistic spirit and simple market-oriented deviation, and the artistic variation in film art due to the loss of aesthetics has constrained the longterm development of Chinese cinema.

1. The market suppresses artistic development. There is a case that can serve as an important starting point for us to think about and to make changes: advertisements placed into films. For the sake of market needs, Chinese films have gradually become the default way to promote the market to pay attention to films, or to make some films acceptable to the market by means of advertisements. Some art films are also forced to use soft advertising to obtain investment. This seems to show that films cannot be separated from the market, but it also shows that when people universally take soft advertising for granted as an important part of film production, the whole value of film gradually mutates. 
What's more, as the market's standards for advertising placement become lower and lower, and the placement of soft ads more and more abrupt, the logic and integrity of the film are also affected. Film, like art, has an integrity of thinking, instead of taking the market norms as the standard, of which the products are obviously entertainment films. The standard of entertainment film is to present the emotion that the market needs, to create according to the thinking of the public and to generate revenue. Succumbing to secular culture and market interests has largely prevented films from being purely artistic. The integrity of artistic creation is to express according to aesthetic interests and the understanding of real life. It is not difficult to find that many films have no choice but to insert advertisements at the request of advertisers, and the hidden ingenuity on the enlarged screen will inevitably expose traces and affect artistic viewing. In an absolute sense, the change of creation for artistic expression is something that affects the whole spirit of artistic creation.

2. "Streaming aesthetics" replaces "thoughtful aesthetics". It is obvious that the aesthetic transmutation caused by the times is permeating the direction of creation, which is mainly influenced by both objective and subjective factors. The aesthetics created in the network era is different from traditional art aesthetics; most obviously the inner "thoughtful aesthetics" is gradually indifferent, while the external audiovisual "streaming aesthetics" is highlighted. Aesthetics is a noble meaning derived from the literati's interest in the ages of words, which needs training to ponder the inner meaning, but also requires people to have a certain cultural literacy, slowly understanding the moral of the aesthetic object, to trigger a wide range of resonance and bring profound inspiration. In this way, beauty or art is a form with meaning, and this aesthetic tendency has always shaped our understanding of emotions, eyes, physical forms, etc. between characters in ancient poems or plays. However, thoughtful aesthetics requires conditions, especially cultivation, time and an observant mind, which have become luxuries for people in contemporary society. The huge amount of information brought by the Internet has made people lose patience and time to analyze carefully, and has urged the gradual departure of thoughtful aesthetics. The so-called streaming aesthetics could be understood as the viral aesthetic. It gets people's attention in the fastest possible time, making them gradually lose the individual choice and interest of self-study. Entertaining films are all about grabbing your attention for a few minutes and bringing out laughter for a few minutes, as the key to attracting the public. However, such films ignore the natural laws of perception, not to mention that the appeal of art is slowly eroded. What is scary is that entertainment is slowly becoming a habit, especially of the new generation, thinking that this is what we reasonably want and consciously sinking into it. It cannot 
be ignored that some researchers have helped to intensify the situation for the sake of their research of the young generation, believing that one's work must submit to the public or the so-called psychology of youth to enter into the market and gain attention. This is obviously based on a standard of appeasing the market and popular culture, discarding the cultural responsibility of cultivating aesthetics and enhancing education. Under the influence of this standard, the aesthetics of the literati gradually becomes alien, and the aesthetics of the public seems to become a reasonable, legitimate and normal choice. However, the essential difference and mutual transformation between the two was discarded. The purpose of art is not for simple material production, but to feel leisure outside the time of material production, the joy of life and the beauty of nature. It is extremely necessary for art works to convey the kind of relaxing spiritual and emotional satisfaction that people desire, and it is also the basis for the existence of art. For a long time, secular culture and market interests have increasingly encroached into the space of art. Yet this spiritual preoccupation, which needs to transcend worldly acquisition and reinforce self-consciousness, gives way to the goal of group convergence and gain, losing the emotional aesthetic of spiritual perception of the world and allowing the market's sole standard to dispel the value of aesthetics. It is widely believed that good work equals good market results, and in the case of art, neither creation nor reception is an individual and unique innovation. In fact what people like is still the feeling that art contributes to people. The magic of thoughtful aesthetics is exemplified when the two main characters look at each other speechlessly in the prison visitation scene in Better Days.

3. Group characteristics obliterate individual characteristics. There is no doubt about the significance of individuality in the creation of art, with its everchanging individual feelings and needs, leading to the wonderful harvest of discovering the unique things of other individuals, and meeting people's different needs and stimulating a variety of unique feelings. Obviously, herd mentality has created the current rise of fan groups, such that the creation of film has to succumb to the commonality of the market. It will be difficult to cultivate initiative and creative consciousness if we choose to swim with the tide, instead of nurturing independent thinking. Cultivating aesthetic initiative is related to the creation of aesthetics. Aesthetics based on the inner perception of life, with a unique sensitivity towards the beauty of life, and individual expression are all a part of spiritual creation. A work of course needs to be understood by the audience, who, through reading and watching, recreates the work and generates new understandings, a process that is also the spiritual composition of serial creation. Both the creation and the acceptance of the recreation of understanding is a process guided by the aesthetic spirit. But we 
gradually find that art becomes, from time to time, a passive perception. The market principle, based on pandering to the audience, together with the principle of public acceptance, replaces the idea that art should stimulate each individual in a common aesthetic atmosphere. By neglecting the goal of nonutilitarian aesthetics but agreeing with the market's standard of shared profitability, the creation of art from the very beginning has to speculate on the market's needs and the so-called habits of the majority, and creation becomes an object of profit calculation. However, both creators and viewers, as well as critics, are slowly acquiescing to passivity, and film and television creations are increasingly catering to the market and even using big data to prove the success of their works, so as to get maximum benefits by adapting their creations to market demands. The film market has already suffered from the phenomenon of youth films, action films, comedies and so on, because they avoid controversy, which leads to the adoration of fans rather than personal appreciation of diversity, and inevitably forms a convergence bias in artistic perception. Generally speaking, the fans' admiration is certainly psychologically justified, but it is not necessarily an appreciation of art, and instead constitutes a blind group obedience and causes damage to aesthetics. Individual artistic creation may not be acceptable to the public, but the unique artistic aesthetic becomes an exclusive object that requires deep thought. How can a solidified perception meet the spirit's constant expectation for novelty? Not to mention the unique thinking toward philosophy, and the inability to accept innovations required by constant advancement of the times. For example, modern dance after ballet, modern poetry after classical poetry, South American magical realism after traditional fiction, postmodern installation art after traditional art, and so on. The suppression of this individual creativity has turned into conformity to the market. Instead of encouraging new ideas with individual aesthetics, it suppresses innovation with the commonality of the group market, resulting in an art that is narrow and secular. Art will obviously carry the preference of self, and inevitably carry the paranoia of artistic perception and multiple meanings, which in fact is a rich complement to the objectivity of aesthetics. People appreciate the personalized and moving charm of the young director Bi Gan's "Little Jasmine" song in the long, long shot of Kaili Blues (Lubian yecan, 2015), which seems to overflow with dull Mercedes on the highway, and remains unforgettable.

4. Rational analysis of the fan club. One cannot ignore the danger of the current group aesthetic after the rise of fan club. The aesthetics of fans is extremely subjective and group-oriented, leading to a gradual shift from pluralism to singularity. In recent years, fans have increasingly become the target group for 
creators to cater to, and the fan economy has become an object that creators dare not ignore, leading to a narrower aesthetic, slowly becoming a tool for works to adapt to the market or even to strengthen the interests of certain interest groups. In 2017, rabid fans created a unique "session-locking" in the Chinese film market to maintain illusory box office results, meaning that the authenticity of the market was greatly undermined. "Session-locking” refers to locking cinema schedules by buying a few tickets for certain sessions in advance to prevent the cinema from withdrawing the schedule and thus affecting the box office. "After the release of the film version of Once Upon a Time (Sanshengsanshi shili taohua, 2017) starring Liu Yifei and Yang Yang, their fans spontaneously organized 'session-locking' in many theaters. According to reports, 42,091 sessions in 53 key cities of concern nationwide were 'locked', with some theaters losing 40,000 yuan in ticket sales in a single day due to 'session-locking'. Many theaters fought against this by citing reasons such as machine and equipment failure, sold-out venues, or raising ticket prices to over 1000 yuan. The conflict between fans and theaters escalated, with theaters even forcing refunds. The war between 'session-locking' and 'antisession-locking' has become a big drama in the film market” (Li 2017). The fans' paranoia towards 'session-locking', and the phenomenon of young idols dominating the market attention in recent years, has damaged the order of the art market, and moreover destroyed the rules of creative production. When the creation of movies depends on the needs of age group and fan preferences, it leads to the unreasonably high pay for young idols, reduces the quality of creation, raises the cost of films, and replaces the content-oriented standards with external selection. In that case, creators cannot fully express their authentic perception of life and promote aesthetic interests from within. The key is that films are no longer competing for the market to meet aesthetic needs, but are driven by profit. At the same time, fan clubs and the popularity of young idols increasingly show a tendency to no longer focus on creative expression. It's a good sign that young idols being criticized and abandoned by the market are starting to withdraw, since it is against the law of art to only focus on speculating which idol has the biggest fan club, the largest market appeal and can ensure the success of the box office, while ignoring the content of film. "The phenomenon that the pay of movie stars in one film or television work can account for more than $50 \%$ of the total cost is common in the Chinese film market, while being almost impossible in the market of the United States, Japan, South Korea and other countries" (Sina Finance and Economics News 2016). The development of art aesthetics has gone through ups and downs 
under the influence of the fan economy, and the presentation and appreciation of individuality has become niche, making popular interests and artistic interests increasingly opposed, such that films well received by audiences do not sell well at the box office, and films that sell well at the box office are often criticized by audiences. For several years, this has become a common phenomenon which is unreasonable but almost normal, and the unity of aesthetics has been fragmented. We need to change this tendency, so that aesthetics can return to its essence, and establish the concept that aesthetics is a blend of diversity and individual creation, and that art creation should be adapted to the masses but should also be harmoniously blended with individual creation.

5. The mainstream creation cannot give up aesthetic expression. As a medium of cultural communication, film should focus on the public interest of the market, with artistic aesthetics being the best lubricant. If ideology becomes as profitoriented as the market, it will certainly be counterproductive. When artistic aesthetics is not considered to be the core of film creation, the consequences of the market's decisive role are obvious. However, the inducement of policies and the reinforcement of public interest can also have an impact on people's aesthetics and influence the direction of artistic creation. The guidance of policy in each historical period has its own cultural needs. But when policy becomes an important guiding factor, or an authoritative requirement, the spirit of artistic creation and expression may be changed as a result. If we create works purely out of the encouragement, support and guidance of policies given to certain themes, there will often be themes such as the stories of college students, village officials, and teachers in poor areas, which experienced a boom some time ago. The diversity of such stories should reflect the diversity of life and focus on artistic expression, but since these themes must be directed or encouraged by certain policies, it is inevitable that artistic expression and the infectious power of the stories will be neglected and eventually become uniform and boring, and the presented works will eventually lose their individuality and emotions, becoming an interpretation of policies. Practice has proven that works that do not conform to the reality of life and are purely products of imagination are narrow art. On the other hand, works that show the feeling of life will definitely have a human touch and uniqueness. For example, Guan Hu's Mr. Six (Laopaoer, 2015) is praised for its portrayal of the characters and the depth of their lives, even though its theme and content are realistic. It is time for film art to reach the core stage of strengthening artistic and aesthetic expression. The Founding of an Army (Jianjun daye, 2017), produced by Huang Jianxin and directed by Andrew Lau, has made innovations in many aspects. 
Instead of using typecast actors as usual, the film chose many young actors to portray this historical story. This break with tradition was met with criticism at the beginning, including comments from the families of the martyrs during the August 1 Nanchang Uprising, "Ye Da Ying wrote in his microblog: 'The history of the revolution is being turned into entertainment, which is a humiliation and distortion of it. As a descendant of General Yeh T'ing, I would like to ask Huang Jianxin (executive producer) and Andrew Lau (director), do you really not know history? Or do you have an ulterior motive to use a major historical event to make money? Who are you insulting when you cast this fresh meat who can't even stand up straight?"' (Guan 2017). The fact is that old rules may not necessarily be unbreakable, and artistic creation requires constant exploration. Restricting creation with a certain theme or other rigid rules will not help creativity. Wolf Warriors 2 is an eye-opening presentation of the transcendence of the hero's personality and national responsibility. “Wolf Warriors 2 breaks the constraints of its theme, making the protagonist Leng Feng a character with both the lone wolf characteristics of a Western hero and the characteristics of an Eastern hero loyal to his country and people, invariably breaking the conceptual model of traditional mainstream films in which the character seems to be impeccable and infallible. The boldness and success of Leng Feng's portrayal lies in the fact that he stands out from traditional restrictions, transcends the mundane and has a unique personality and superhuman quality" (Zhou 2017a, 2017b). Restricted works are aesthetically deficient in fostering artistic expression and appreciation. Many of our works are created according to a social concept rather than a personal feeling, according to a policy requirement rather than a sense of reality derived from life. They are created according to a variation of a theme, rather than according to a theme based on his inner impulse. The wide popularity of the red classic film The Taking of Tiger Mountain (Zhiqu weihushan, 2014) lies in the innovation of the old tradition, which deserves recognition. The success of this innovation provides a good experience for the production of melodramatic movies, but by the same token, the film also has obvious aesthetic flaws, such as not highlighting the characteristics of the hero by portraying inner emotions, although the effect presented by the picture is awe-inspiring, such as the scenes of tanks and cannons driving into the deep mountains, it is not a perfect creation reflecting reality. Operation Mekong does go beyond the usual in terms of police storytelling for its innovation. It is possible to create a moving work by producing from reality, starting from emotions, and developing from the inner logic of the narrative. The spirit of aesthetics is to constantly create beautiful things. In fact, creation based on the emotions of the human heart requires constant innovation of artistic feelings, and realization of the needs of the audience. Whether the 
American film Inception (2010) presents a science fiction world, or the Chinese film Wolf Warriors 2 breaks the traditional limits, they all meet the expectations of the audience.

\section{Rational Analysis is the First Step to Changing the Status Quo}

Chinese cinema is developing more and more deeply in terms of artistic expression, entering a stage that can be called the fourth Chinese film climax. Whether it is the fact that Chinese cinema is the second largest producer in the global market, the first in the world in terms of the number of screens, and the second or third in terms of the number of films produced each year in the world; or the fact that in recent years Chinese cinema has adhered to its own creative aesthetic tendencies in a special context, with the film The Eight Hundred (Babai, 2020) winning the first place at the global box office in 2020, all deserve praise. Looking at the developmental trend of Chinese cinema in recent years, there are several conditions that deserve special consideration and analysis. Chinese films should create their own aesthetic world based on market construction, so as to provide a good foundation for the long-term development and solid survival of Chinese cinema.

(i) Seeing specific or big-picture impact issues.

1. To make the aesthetic concept of Chinese cinema more clearly established nowadays. Chinese cinema needs to change its featureless and unclear appearance. While film diversity needs to be maintained, the performance of film concepts is not pure enough, and the attitude towards artistic aesthetics is gradually indifferent. We should be wary of a market that shows disorder and is eager to achieve profit. In fact, the utilitarian nature of the market is one of the causes of today's chaos. In the Internet era, the market has abandoned its adherence to art in order to satisfy the desires of fan groups, the shift of the new generation's cultural language has affected the aesthetic tradition of cinema, the wandering of creative subjectivity leads lack of distinctive style, and the overemphasis on technology has led to the neglect of the aesthetic spirit. Internally, we need to establish the aesthetic values of Chinese cinema and form a group of aesthetic and cultural projection objects; externally, we need to create a symbolic label to cover the overall aesthetic form of Chinese cinema, which can be called “Chinese cinema school”, such as Hollywood's high-tech creation and genre films, Bollywood's singing and dancing, Iranian cinema's quiet style, Japanese cinema's "chrysanthemum and sword", etc. 
2. Revision works are similar and lack individuality. The commonality of Chinese films prevails, and individuality is gradually lost, from the situation where various types of films such as martial arts films, youth films and comedies blossom to the situation where IP films are prevalent in recent years, and the space for individuality to survive is restricted. While IP movies under various banners are emerging, movies with innovative content are becoming less and less common, with profit-oriented imitation replacing self-creation. The meaning of film art has become indifferent, making entertainment a spell that is hard to get rid of; the change of motive is the enemy of creation, and instead of creating because of the inner change of deep feelings, it is speculation on market direction and passively following the changes of the market. Only the emergence of more films with characteristics such as Kaili Blues, Dwelling in the Fuchun Mountains (Chunjiangshuinuan, 2019), Crosscurrent (Changjinangtu, 2016), Balloon, etc., which express regional characteristics, can foster the personalized development of Chinese cinema.

3. The regeneration of creative teams. A generation of filmmakers, who have already achieved considerable success, including Zhang Yimou, Chen Kaige, Jiang Wen, Feng Xiaogang, and Huo Jianqi, still persist in their creations, but always face the challenges and crises of the current market. They are still trying to express their own values and artistic style, but are questioned from time to time, yet they are a generation that can never be replaced. How to encourage and care for this group of creators who insist on presenting aesthetic culture in Chinese films is a reflection of whether Chinese cinema itself has a spirit of tolerance. The core generation of Chinese cinema is divided from time to time, a group of relatively young creators, such as Wang Xiaoshuai, Jia Zhangke, Guan Hu, Zhang Yang, Wuershan and so on, who still maintain their individuality in creation, but also another group of guardians of the creation and perseverance of Chinese film art and culture. However, the new upstarts still struggle to achieve greatness. The newly emerged generation is uneven. Films such as Crosscurrent, The Master (Dashi, 2015), Cock and Bull (Zhuixiongzhe ye, 2106), Kaili Blues, The Piano in a Factory (Gangdeqin, 2010) have stood out, but it seems that the traditional spirit of Chinese cinema's group creation still needs to be strengthened. Director Zhang Yimou's artistic presentation in the film Cliff Walkers represents the pursuit of mature directors, and Jia Ling's first time as a director won the highest female director at the global box office with $\mathrm{Hi}$, Mom (Nihao Lihuanying, 2021), all of these achievements represent the continuous exploration of the new class of directors and prove that the new era requires the concerted efforts of creators. 
4. Changing audiences and aesthetic tastes influence the development of cinema. The new generation is subject to the influence of film trends, including advertising and anime, and is more interested in Hollywood technology and in seeing stars in movies. Opinions and criticism circulate very quickly on the Internet and influence each other, resulting in film works often becoming a group entertainment choice. Some viewers may even arbitrarily judge current works based on the previous works of some directors, and irrational subjective emotions may cause greater harm to the evaluation of creative works. It is important to believe that new audiences have a certain degree of acceptance for artistic and aesthetic expression, and that works that create a true representation of life and truly reveal the psychological and artistic emotional richness of characters are bound to be welcomed by new audience groups. A Little Red Flower is highly infectious for different age groups, and Hi, Mom moves audiences young and old, all of which are excellent works that illustrate the above.

(ii) Changing concepts to create a new view of film

The implementation of artistic and aesthetic expression naturally corresponds to the concept of market, so it needs to be noted that:

1. First of all, we need to change the assumption that the market should be the only standard. In fact, the market is only the test for the popularity of one film among the audience, but it should not be the only criterion for judging the work. We do need to pay attention to the audience's recognition, which is also an important factor in the realization of the value of film. Creating for the intrinsic requirements of the market is used to test whether the author has kept up with the trend of the times, but in no way does it mean that the acceptance of the market is justified, and that the aesthetic value of creation is fundamental. If there is no market or attention for any movie, it is necessary to reflect on whether it is misplaced or ahead of its time, or even whether it is making a new innovation. In short, market survival cannot be the whole reason for creative survival. In particular, it should be clear that whether it is creation or criticism, the greatest danger is to replace the market acceptance of films with an essential judgment of film art, without understanding the high or low value of aesthetic culture, completely rejecting the connotation of film creation, and being unable to objectively appreciate films and evaluate their artistic value.

2. Continuously researching and adapting to the audience's preferences and needs is not to passively submit to them, but to conform to the context of the times and find the direction that guides the aesthetic expression of art. Reasonable market indicators will lead us to pay attention to the changing 
audience of the times, such as the psychological analysis of the current audience group of about 21 years old, etc., in order to have a grasp of the audience group, but not to replace everything. Importantly, studying the passive consciousness of the audience is never what culture does. The cognitive age group characteristics were originally sought to be elevated in order to know and find closeness, in order to create the possibility of active guidance. Just as for 10 years, we have some misconceptions that to adapt to children we need to bend down to fit them, while ignoring one of the most important things, which is that we need to elevate children to stand up and give them the ability to think autonomously, even philosophically, to perceive the world. So we relish some animal cartoons in the early childhood stage, only to be left with childish stories that happen between various animals, lowering the standard of our entire cartoons. Aesthetic or philosophical thinking is crucial for human beings, while film, as the latest visual cultural product, should be more of a guide to meet the audience's demands and reflect the future, instead of yielding to some of the socalled audience's needs. When the market becomes the only standard, when the audience becomes the default indicator, our most important goal should be to lead the direction of cultural development and make it climb again, which is slowly fading or even disappearing. A choice built on the right view of the audience cannot be simply a goal of profit, but a goal of leading a positive spirit. We should never make it our sole task to satisfy the needs of the audience, not in the same way that the singularity of that educational approach of training college students simply to fit into some established employment, rather than training them to be leaders in creating the world, transforming it and creating new ways of life, both are equally dangerous. The same is true of film culture. If one simply takes the needs of a certain type of film audience as the target, such as that of the audience of Tiny Times, and then to submit, to imitate, to guess the theme they like, it will naturally result in the hollow ignorance of the youth genre in terms of story content, and even attract more genre films become more and more boring.

3. For a long time, the Chinese cinema has held up Hollywood as the standard for film production. There are many factors that contribute to the success of Hollywood films, such as high technology, nationalism, cultural strength, strong economic measures, market manipulation ability, etc., which are all worth learning. But in adopting the Hollywood model, it is obviously insufficient and parochial to simply imitate its forms, especially the so-called genre films. Genre films do not satisfy all aesthetic needs; they are designed in a fixed form to achieve commercial value and meet the needs of a specific audience. The Hollywood model is more of an aesthetic business model that adapts to the interests of Western audiences and reflects Western values, but how can it transcend the cultures of different countries and be universally applicable? 
Hollywood is constantly adding new elements and creating new genres, and its films implicitly propagate Westernism and Statism. While it is necessary to study external forms, it is clearly inappropriate to use them as the only criteria. We should have a traditional aesthetic concept. To forget the uniqueness of Chinese culture and Chinese aesthetic culture and to follow the same pattern of Hollywood is against the idea of absorbing creativity in Eastern culture. Hollywood has its own advantages, and learning from its successes is good for broadening our horizons and seeing the common appreciation of human interests. We should, in turn, learn from the Hollywood films' grasp of human psychology, aesthetic interests, and the commonality of beauty, instead of relinquishing the advantages of psychology, characterization, and the grasp of emotions. We should also create film genres that only belong to Chinese culture and focus on the expression of emotions. Chinese audiences are full of expectations for innovation and breaking the stereotypes of the genre. Operation Mekong and Wolf Warriors 2 are typical examples. As long as the creators have great desire and enthusiasm, and can devote themselves to bring forth the new through the old and express Chinese distinctively emotions and behavior, they can create great value and market interest. On the contrary, superficial imitations, such as the formulaic youth film series, quickly lose their viewing interest. Both positive and negative examples prove that movies, as an important part of art and culture, need to constantly innovate, reflect real life, and create new images in order to achieve a new world of cinema.

\section{Conclusions}

Chinese cinema has the conditions to create new market revenue and achieve aesthetic ideals, and it is the first priority for Chinese cinema to follow the road of market development to strengthen artistic expression and national culture, to firmly establish the image of "Chinese film school" containing excellent works and adhering to core values and culture (Zhou 2017a, 2017b). Realizing a new situation of Chinese film culture should become a common goal pursued by the whole industry. It is thus necessary to emphasize the following points:

First of all, Chinese cinema should reflect reality and truly express the aesthetic interest of daily life. For example, Mr. Six reflects the reality of daily life; $\mathrm{Hi}$, Mom, the public psychology, and Cliff Walkers, the convergence of mainstream values and commercial characteristics of spy films.

Secondly, Chinese films must show a unique cultural expression and understanding of aesthetics with Chinese characteristics, and express inner feelings in a serious way. Films in the past such as Springtime In a Small Town (Xiaocheng zhi 
chun, 2002), My Memories of Old Beijing (Chengnan jiushi, 1983), Postmen In The Mountains (Nashan naren nagou, 1999), etc., and films in recent years Kaili Blues, Crosscurrent, Dwelling in the Fuchun Mountains, etc. are all examples of this kind.

Thirdly, we should encourage more individual creations in Chinese films, whether they are works that explore new knowledge and feelings of life, or creations that create spiritual sensations, just like the documentary 22 and Paths of the Soul.

In addition, we hope that Chinese films should have better aesthetic standards, a grand imagination, and also the publicity of national heroism. This change is presented from films such as Wolf Warriors 2 to the new mainstream film My People, My Country and My People, My Homeland (Wo he wode jiaxiang., 2020).

And remember, from the perspective of aesthetic appreciation, it is a top priority for Chinese films to be more in line with reality and traditional culture. All these should be based on a foundation, that is, the criteria for judging the aesthetics and culture of Chinese cinema should be measured by Chinese culture, Chinese values, and the criteria of Chinese visual culture, rather than simply applying the standards of foreign countries. This is an increasingly important issue of the times for the reconstruction, establishment and development of Chinese visual culture.

Acknowledgements: I would like to thank the support of Professor Haina Jin and the translation project she headed, as well as the translator Zixuan $\mathrm{Gu}$ and the copyeditor for their dedicated and excellent work.

Research funding: The research of this article is supported by Bejing Film Academy, the China National Social Science Major Research Project in Arts "Research on the Construction of the Theoretical System of the Chinese Film School” (Grant number: 18ZD14).

\section{References}

Btime. 2017. Zhanlang 2 haiwai shichang huo haoping, haolaiwu 6 da gongsi da 15 tong dianhua paidui yaoyue [Wolf Warriors 2 Well Received in Overseas Markets, Six Major Hollywood Companies Made 15 Calls to Invite Wu Jing]. Also available at https://www.sohu.com/a/ 193488960_99915785.

Dong, Q. 2017. Chunjie shuqidang huobao zhu zhongguo 2017 nian piaofang po 400 yi, bi qunian kuaile 74 tian [40 Billion Chinese Box Office in the Spring Festival in 2017,74 Days Faster than Last Year]. Also available at https://t.qianzhan.com/caijing/detail/170905-b6b224dc.html.

$\mathrm{Fu}, \mathrm{X}$. 2017. BBC baodao Zhanlang 2 gao piaofang, haiwai bufen yingyuan yipiaonanqiu [BBC: Wolf Warriors 2 Gets High Box Office, with Tickets in Some Overseas Theaters Out of Demand]. Also available at https://ent.ifeng.com/a/20170806/42964831_0.shtml. 
Guan, L. 2017. Ye Daying paohong Jianjun daye nianqing yanyuan, wangyou: wudifangshi [Ye Daying Slammed the Actors of The Founding of an Army, While Netizens Counterattacked him for Shoot at Random]. Also available at http://www.chinanews.com/yl/2017/07-27/8289110.shtml.

Li, S. 2017. Fensi ‘suochang' yu qiangxing tuipiao zhizheng [The War Between 'Session-Locking' and 'Anti-Session-Locking']. Also available at https://www.sohu.com/a/164980907_161623.

Liu, Q. 2017. Ershier huo 1.7 yi piaofang, yishu dianying ruhe dida zuida guanzhongqun? [Twenty Two Hit 170 Million Box Office, How Art Films Arrive the Largest Audiences?]. Also available at http://ex.cssn.cn/wh/wh_whrd/201709/t20170913_3638560.shtml.

Sina Finance and Economics News. 2016. Zhongguo mingxing pianchou quanqiu hanjian, yi gaoda yingshiju zhizuo chengben $70 \%$ [Chinese Stars' Remunerations are Rarely Seen in the World: Accounting $70 \%$ of the Production Cost of the Films and Television]. Also available at http://gd.sina.com.cn/finance/industry/2016-09-09/cj-ifxvukhx4666514.shtml.

Xiao, M. 2017. Zhuanfang Hubuwu daoyan: lishi de cuowu bei chuancheng hennan gaibian [Interview on the Director of Foxtrot, It is Hard to Change the Inherited Historical Mistakes]. Also available at https://ent.ifeng.com/a/20170905/42972822_0.shtml.

Zhou, X. 2017a. Zhanlang 2 weihe ruci chenggong [The Secret of the Success of Wolf Warriors 2]. Also available at http://www.rmlt.com.cn/2017/0911/494989.shtml.

Zhou, X. 2017b. "Constructing Chinese Film School: Conceptual Exploration and Adaptation of Communication Perspectives.” Modern Communication 39 (11): 67-73.

\title{
Bionote
}

\author{
Xing Zhou \\ Beijing Normal University, Beijing, China \\ xcnz001@163.com
}

Xing Zhou has long been engaged in the research of the history of Chinese film and television, and the communication of film and television culture. He is the former dean of the School of Arts and Communication at Beijing Normal University. Currently, he is the director of the Center for Arts Education and Research at Beijing Normal University and the National Demonstration Center for Experimental Education "Communication and Art Experimental Teaching Center". He also serves as the chair of the Education Supervisory Committee of Drama, Film and Television in colleges of the Ministry of Education, vice chair of the National Education Supervisory Committee of Master of Fine Arts, a member of the National Art Education Committee of the Ministry of Education, a member of the New Liberal Arts Construction Group of the Ministry of Education, and the vice president of the Chinese Collegial Association for Visual Art, and the president of the Film and Television Education Committee, the vice president of the China Film Critics Association, the vice president of the China Artistic Theory Academy, the executive vice president of the Chinese Academy of Aesthetic Education in Higher Education, the vice chairman of the Theory and Criticism Committee of the China Film Association, vice chairman of the Audiovisual Committee of the China Literature and Art Critics Association, etc. 


\section{Zixuan Gu}

Communication University of China, Beijing, China

Zixuan Gu is a postgraduate in the School of Foreign Languages and Cultures at the Communication University of China. Her translation of this academic paper is supported by the China National Social Science Major Research Project "General History of Film Translation in China" (Grant number: 20\&ZD313). 